\title{
Synthesis of Novel 1,2,4-Triazole Derivatives as Antimicrobial Agents via the Japp-Klingemann Reaction: Investigation of Antimicrobial Activities
}

\author{
Tasneem Taj, Ravindra R. Kamble, Atukuri Dorababu, and Gangadhar Y. Meti \\ Department of Studies in Chemistry, Karnatak University Dharwad, Dharwad 580 003, India \\ Correspondence should be addressed to Ravindra R. Kamble; kamchem9@gmail.com
}

Received 30 May 2013; Revised 5 August 2013; Accepted 11 August 2013

Academic Editor: Ponnurengam Malliappan Sivakumar

Copyright @ 2013 Tasneem Taj et al. This is an open access article distributed under the Creative Commons Attribution License, which permits unrestricted use, distribution, and reproduction in any medium, provided the original work is properly cited.

In the present investigation, 1,2,4-triazole appended to pyrazoline and pyrazole rings (4a-g) using $\mathrm{N}$-arylsydnone as synthon was prepared. The title compounds were subjected to Osiris property explorer for the oral bioavailability to analyze their drug likeness and drug score. Further, the compounds were subjected to the antimicrobial activity and analyzed the IC 50 and MIC values.

\section{Introduction}

3-Arylsydnone, a class of mesoionic compounds, has been used as synthon extensively for the synthesis of various pharmaceutically potent molecules like pyrazole, phenylindazole, carbazole, pyrazoline, tetrazine, and 1,3,4-oxadiazole by 1,3dipolar cycloaddition and addition elimination reactions [13]. On ring insertion with hydrazine hydrate, 1,3,4-oxadiazole yields 1,2,4-triazole derivative [4]. 1,2,4-Triazolinone derivatives such as azafenidin and sulfentrazone have been reported as herbicides [5-9]. Synthesis of 1,2,4-triazoles fused to another heterocyclic ring has attracted wide spread attention due to their diverse applications as antibacterial, antidepressant, antiviral, antitumor, anti-inflammatory agents, pesticides, herbicides, dyes, lubricant, and analytical reagents [10].

There is a considerable interest in chemotherapeutic activity of pyrazole derivatives. They have been reported to exhibit broad spectrum of biological effects [11]. Pyrazoles also possess a broad spectrum of biological effectiveness such as antidepressant [12] and antibacterial activity [13]. Besides, great interest in the pyrazole molecule has been stimulated by some promising agrochemical applications such as herbicides and fungicides [14-16]. Pyrazole-1-carboxamidopyrazole and 1-thiocarbamoyl-pyrazole showed impressive in vivo antitumour activity in experimental animals. One of the series of azoxypyrazoles, that is, $1,1^{\prime}$-bis(2-hydroxyethyl)-3,5, $3^{\prime}, 5^{\prime}$ tetra methylazoxypyrazole, has been reported to possess activity against ascitic forms of the Ehrlich, Landschiitz, and Sarcoma 180 tumours and against the P.388 lymphatic leukaemia in mice [17]. In view of these observations, we herein report the synthesis of novel molecular scaffolds containing pyrazole, pyrazolines, and 1,2,4-triazole ring using $\mathrm{N}$ arylsydnone as a synthon in the hope to get lead compounds as antimicrobial agents.

\section{Experimental}

Melting points were determined in open capillaries. The IR spectra were recorded on Nicolet Impact 5200 USA FT IR using $\mathrm{KBr}$ pellets. ${ }^{1} \mathrm{H}$ NMR spectra were recorded on Bruker Varian 300-MHz FT NMR spectrometer with TMS as internal standard. EI mass spectral analyses were recorded on Shimadzu Japan QP2010 S model spectrometer, and elemental analyses were carried out using Heraus $\mathrm{CHN}$ rapid analyzer. The purity of the compounds was checked by thin layer chromatography (TLC) on silica gel plate using hexane and ethyl acetate. The pharmacological evaluation was carried out at the Biogenics, Hubli, Karnataka, India. The $c \log P$ values have been calculated using the Osiris molecular 
property explorer software for the structural analogues of the synthesized compounds and are uncorrected. The Schiff bases 2-[4-(1-acetyl-5-phenyl-4,5-dihydro-1H-pyrazol-3-yl)phenyl]-4-alkyl/arylamino-5-methyl-3-oxo-2,4-dihydro$[1,2,4]$-triazoles (1a-g) were prepared as per the reported procedure [4]. Characterization and Spectral data of synthesized compounds are tabulated in Tables 1 and 2, respectively.

\section{Synthesis of 2-[4-(1-Acetyl-5-alkyl/aryl-4,5- dihydro-1H-pyrazol-3-yl)phenyl]-5-methyl- $4\{(4-a m i n o$ phenyl) methylideneamino $\}-2,4-$ dihydro-3H-1,2,4-triazol-3-one (2a-g)}

To a mixture of compound $(\mathbf{l a}-\mathbf{g}, 0.50 \mathrm{~g}, 0.001 \mathrm{~mol})$ and tin $(0.0015 \mathrm{~mol})$, concentrated $\mathrm{HCl}(3.0 \mathrm{~mL})$ was added dropwise and refluxed on water bath until the solution becomes clear (approximately $30 \mathrm{~min}$ ). The reaction mixture was then cooled and made alkaline by the addition of aqueous $\mathrm{NaOH}$ solution. The amino derivative thus formed was extracted with THF. The amorphous pale brown compound ( $2 \mathbf{a}-\mathbf{g})$ was obtained after evaporation of the solvent and purified using methanol/ethanol.

\section{Synthesis of 3-[2-\{4-(E-(-[(1-Acetyl-5-p-a nisyl-4,5-dihydro-1 $H$-pyrazol-3-yl)phenyl]- 5-methyl-3-oxo-4H-1,2,4-triazol-yl)imino methyl $\}$ phenylhydrazinylidene]-pentane- 2,4-dione (3a-g)}

The amino derivative $(\mathbf{2} \mathbf{a}-\mathbf{g}, 0.001 \mathrm{~mol})$ was diazotized in $\mathrm{HCl}(0.40 \mathrm{~mL})$ with cold solution of sodium nitrite $(0.20 \mathrm{~g}$, $0.001 \mathrm{~mol}$ in $2.0 \mathrm{~mL}$ of water) during a period of 45 minutes at $0-5^{\circ} \mathrm{C}$. The diazotized solution was treated with acetylacetone $(0.001 \mathrm{~mol})$ and sodium acetate $(0.005 \mathrm{~mol})$ in ethanol $(10 \mathrm{~mL})$ during 15 minutes and further stirred for one hour. The reaction mixture was then poured into water and the solid obtained was collected by filtration and crystallized from ethanol to get intermediate $3 \mathbf{a}-\mathbf{g}$.

\section{Synthesis of 4- $\{[E-\{4-[(E)-(3,5-$ \\ Dimethyl-1H-pyrazol-4-yl)-diazenyl] phenyl\}methylidene] amino\}-5-methyl-2- (1-acetyl-5,4-hydroxylphenyl-4,5-dihydro- $1 H$-pyrazol-3-yl)phenyl-2,4-dihydro-3H- 1,2,4-triazol-3-one (4a-g)}

A mixture of compound $3 \mathbf{a}-\mathbf{g}(0.0001 \mathrm{~mol})$ and hydrazine hydrate $99 \%(0.004 \mathrm{~mol})$ in ethanol $(15 \mathrm{~mL})$ was refluxed on a water bath for about $8 \mathrm{~h}$. The solid obtained after cooling was filtered and washed with hot ethanol to get compounds 4a-g. Recrystallization from ethanol afforded the pale brown crystals.

\section{Molecular Osiris Property Explorer $[18,19]$}

In view of the biological properties of azopyrazolobenzylidene derivatives as described in the introduction, it was thought of subjecting the newly synthesized molecules to molecular Osiris property explorer. Prediction of toxicity, drug likeness, and drug score by the computer programme Osiris provides the basis to avoid the experimental study of potentially harmful substances. In Osiris, toxicity risk assessment predicts mutagenicity, tumorigenicity, and irritating and reproductive effects. The Osiris property explorer is an integral part of Actelion's in-house substance registration system developed by Thomas Sander at Actelion Pharmaceuticals Limited, Switzerland. The prediction process relies on a precompiled set of structure fragment that gives rise to toxicity alerts in case they are encountered in the structure currently drawn. These fragment lists were created by rigorously shredding all compounds in the database known to be active in a certain toxicity class. During shredding, the molecule was cut at every rotatable bonds leading to a set of core fragments. These in turn were used to reconstruct all possible bigger fragments being a substructure of the original molecule. Afterwards, a substructure search process determines the occurrence frequency of any fragment within all compounds of that toxicity class.

\section{Antimicrobial Assay $[20,21]$}

The protocol for antimicrobial activity assay was as follows.

7.1. Antibacterial Assay. Agar diffusion method was used to analyze the bacteria $S$. typhi and B. pyogenes. The standard antibiotic used was gentamycin. The media used was peptone $(10 \mathrm{~g}), \mathrm{NaCl}(10 \mathrm{~g})$, and yeast extract $(5 \mathrm{~g})$ and agar in $1000 \mathrm{~mL}$ of distilled water. Initially, the stock cultures of bacteria were revived by inoculating in broth media and grown at $37^{\circ} \mathrm{C}$ for $18 \mathrm{~h}$. The agar plates of the above media were prepared and wells were made in the plate. Each plate was inoculated with $18 \mathrm{~h}$ old cultures $\left(100 \mu \mathrm{L}, 10^{4} \mathrm{cfu}\right)$ and spread evenly on the plate. After $20 \mathrm{~min}$, the wells were filled with different concentrations of samples. The control wells were filled with gentamycin. The sample preparation was done as $20 \mathrm{mg}$ sample dissolved in $1 \mathrm{~mL}$ of solvent (DMSO). The stock sample concentration was $20 \mathrm{mg} / \mathrm{mL}$. The concentrations screened were $0.0625,0.125,0.25,0.5,1.0$, and $2.0 \mathrm{mg}$. All the plates were incubated at $37^{\circ} \mathrm{C}$ for $18 \mathrm{~h}$, and the diameter of the inhibition zones was noted, and MIC values are presented in Table 3.

7.2. Antifungal Assay. The fungi analyzed were A. niger and C. albicans. The standard antifungal used was amphotericin B. The media used was Czapek-Dox agar: composition $(\mathrm{g} / \mathrm{L})$ sucrose $(30.0 \mathrm{~g})$, sodium nitrate $(2.0 \mathrm{~g}), \mathrm{K}_{2} \mathrm{HPO}_{4}(1.0 \mathrm{~g})$, $\mathrm{MgSO}_{4} .7 \mathrm{H}_{2} \mathrm{O}(0.5 \mathrm{~g}), \mathrm{KCl}(0.5 \mathrm{~g}), \mathrm{FeSO}_{4}(0.01 \mathrm{~g})$, and agar $(20 \mathrm{~g})$. Initially, the stock cultures of fungi were revived by inoculating in broth media and grown at $27^{\circ} \mathrm{C}$ for $48 \mathrm{~h}$. The agar plates of the above media were prepared and wells were made in the plate. Each plate was inoculated with 
TABLE 1: Characterization data of synthesized compounds.

\begin{tabular}{|c|c|c|c|c|c|c|c|}
\hline \multirow{2}{*}{ Comp. } & \multirow{2}{*}{ Melting point $\left({ }^{\circ} \mathrm{C}\right)$} & \multirow{2}{*}{ Solvent of crystallization } & \multirow{2}{*}{ Yield (\%) } & \multirow{2}{*}{$\begin{array}{c}\text { Formula } \\
\text { (Molecular mass) }\end{array}$} & \multicolumn{3}{|c|}{ Analysis calcd./found } \\
\hline & & & & & $\mathrm{C}$ & $\mathrm{H}$ & $\mathrm{N}$ \\
\hline $2 a$ & $130-131$ & Methanol & 60 & $\begin{array}{c}\mathrm{C}_{27} \mathrm{H}_{25} \mathrm{~N}_{7} \mathrm{O}_{2} \\
(479)\end{array}$ & $\begin{array}{l}67.63 \\
67.62\end{array}$ & $\begin{array}{l}5.25 \\
5.23\end{array}$ & $\begin{array}{l}20.45 \\
20.46\end{array}$ \\
\hline $2 b$ & $140-141$ & Methanol & 62 & $\begin{array}{c}\mathrm{C}_{27} \mathrm{H}_{24} \mathrm{ClN}_{7} \mathrm{O}_{2} \\
\text { (513) }\end{array}$ & $\begin{array}{l}63.09 \\
63.07\end{array}$ & $\begin{array}{l}4.71 \\
4.72\end{array}$ & $\begin{array}{l}19.08 \\
19.05\end{array}$ \\
\hline $2 \mathrm{c}$ & $131-132$ & Methanol & 63 & $\begin{array}{c}\mathrm{C}_{27} \mathrm{H}_{24} \mathrm{ClN}_{7} \mathrm{O}_{2} \\
\text { (513) }\end{array}$ & $\begin{array}{l}63.09 \\
63.08\end{array}$ & $\begin{array}{l}4.71 \\
4.73\end{array}$ & $\begin{array}{l}19.08 \\
19.04\end{array}$ \\
\hline $2 d$ & $123-124$ & Ethanol & 60 & $\begin{array}{c}\mathrm{C}_{27} \mathrm{H}_{24} \mathrm{ClN}_{7} \mathrm{O}_{2} \\
(513)\end{array}$ & $\begin{array}{l}63.09 \\
63.04\end{array}$ & $\begin{array}{l}4.71 \\
4.72\end{array}$ & $\begin{array}{l}19.08 \\
19.05\end{array}$ \\
\hline $2 e$ & $127-128$ & Methanol & 62 & $\begin{array}{c}\mathrm{C}_{28} \mathrm{H}_{27} \mathrm{~N}_{7} \mathrm{O}_{2} \\
(493)\end{array}$ & $\begin{array}{l}68.14 \\
68.12\end{array}$ & $\begin{array}{l}5.51 \\
5.53\end{array}$ & $\begin{array}{l}19.4 \\
19.2\end{array}$ \\
\hline $2 \mathrm{f}$ & $130-131$ & Ethanol & 66 & $\begin{array}{c}\mathrm{C}_{27} \mathrm{H}_{25} \mathrm{~N}_{7} \mathrm{O}_{3} \\
(495)\end{array}$ & 65.44 & 5.09 & 19.79 \\
\hline $2 \mathrm{~g}$ & $119-121$ & Ethanol & 70 & $\begin{array}{c}\mathrm{C}_{28} \mathrm{H}_{27} \mathrm{~N}_{7} \mathrm{O}_{3} \\
(509)\end{array}$ & $\begin{array}{l}65.43 \\
66.03\end{array}$ & $\begin{array}{l}5.06 \\
5.35\end{array}$ & $\begin{array}{l}19.78 \\
19.23\end{array}$ \\
\hline $3 a$ & $141-142$ & Ethanol & 71 & $\begin{array}{c}\mathrm{C}_{32} \mathrm{H}_{30} \mathrm{~N}_{8} \mathrm{O}_{4} \\
(590)\end{array}$ & $\begin{array}{l}65.07 \\
65.08\end{array}$ & $\begin{array}{l}5.12 \\
5.13\end{array}$ & $\begin{array}{l}18.97 \\
18.96\end{array}$ \\
\hline $3 \mathbf{b}$ & $118-120$ & Ethanol & 66 & $\begin{array}{c}\mathrm{C}_{32} \mathrm{H}_{29} \mathrm{ClN}_{8} \mathrm{O}_{4} \\
(624)\end{array}$ & $\begin{array}{l}61.49 \\
61.50\end{array}$ & $\begin{array}{l}4.68 \\
4.69\end{array}$ & $\begin{array}{l}17.93 \\
17.90\end{array}$ \\
\hline $3 c$ & 134-135 & Ethanol & 60 & $\begin{array}{c}\mathrm{C}_{32} \mathrm{H}_{29} \mathrm{ClN}_{8} \mathrm{O}_{4} \\
(624)\end{array}$ & $\begin{array}{l}61.49 \\
61.51\end{array}$ & $\begin{array}{l}4.68 \\
4.68\end{array}$ & $\begin{array}{l}17.93 \\
17.92\end{array}$ \\
\hline $3 d$ & $125-126$ & Ethanol & 60 & $\begin{array}{c}\mathrm{C}_{32} \mathrm{H}_{29} \mathrm{ClN}_{8} \mathrm{O}_{4} \\
(624)\end{array}$ & $\begin{array}{l}61.49 \\
61.49\end{array}$ & $\begin{array}{l}4.68 \\
4.67\end{array}$ & $\begin{array}{l}17.93 \\
17.89\end{array}$ \\
\hline $3 e$ & $112-114$ & Ethanol & 65 & $\begin{array}{c}\mathrm{C}_{33} \mathrm{H}_{32} \mathrm{~N}_{8} \mathrm{O}_{4} \\
(604)\end{array}$ & $\begin{array}{l}65.55 \\
65.53\end{array}$ & $\begin{array}{l}5.33 \\
5.35\end{array}$ & $\begin{array}{l}18.53 \\
18.50\end{array}$ \\
\hline $3 \mathrm{f}$ & $128-129$ & Ethanol & 69 & $\begin{array}{c}\mathrm{C}_{32} \mathrm{H}_{30} \mathrm{~N}_{8} \mathrm{O}_{5} \\
(606)\end{array}$ & $\begin{array}{l}52.36 \\
52.33\end{array}$ & $\begin{array}{l}4.4 \\
4.1\end{array}$ & $\begin{array}{l}18.47 \\
18.49\end{array}$ \\
\hline $3 g$ & $115-116$ & Ethanol & 71 & $\begin{array}{c}\mathrm{C}_{33} \mathrm{H}_{32} \mathrm{~N}_{8} \mathrm{O}_{5} \\
(620)\end{array}$ & $\begin{array}{l}63.3 \\
63.4\end{array}$ & $\begin{array}{l}5.20 \\
5.21\end{array}$ & $\begin{array}{l}18.05 \\
18.04\end{array}$ \\
\hline $4 a$ & $158-160$ & Ethanol & 52 & $\begin{array}{c}\mathrm{C}_{32} \mathrm{H}_{32} \mathrm{~N}_{10} \mathrm{O}_{2} \\
(586)\end{array}$ & $\begin{array}{l}65.29 \\
65.28\end{array}$ & $\begin{array}{l}5.48 \\
5.49\end{array}$ & $\begin{array}{l}23.79 \\
23.78\end{array}$ \\
\hline $4 b$ & $145-146$ & Ethanol & 57 & $\begin{array}{c}\mathrm{C}_{32} \mathrm{H}_{31} \mathrm{ClN}_{10} \mathrm{O}_{2} \\
(622)\end{array}$ & $\begin{array}{l}61.68 \\
61.65\end{array}$ & $\begin{array}{l}5.01 \\
5.02\end{array}$ & $\begin{array}{l}22.48 \\
22.47\end{array}$ \\
\hline $4 c$ & $121-122$ & Ethanol & 68 & $\begin{array}{c}\mathrm{C}_{32} \mathrm{H}_{31} \mathrm{ClN}_{10} \mathrm{O}_{2} \\
(622)\end{array}$ & $\begin{array}{l}61.68 \\
61.65\end{array}$ & $\begin{array}{l}5.01 \\
5.02\end{array}$ & $\begin{array}{l}22.48 \\
22.47\end{array}$ \\
\hline $4 d$ & $143-144$ & Ethanol & 64 & $\begin{array}{c}\mathrm{C}_{32} \mathrm{H}_{31} \mathrm{ClN}_{10} \mathrm{O}_{2} \\
(622)\end{array}$ & $\begin{array}{l}61.68 \\
61.65\end{array}$ & $\begin{array}{l}5.01 \\
5.02\end{array}$ & $\begin{array}{l}22.48 \\
22.47\end{array}$ \\
\hline $4 e$ & $130-132$ & Ethanol & 70 & $\begin{array}{c}\mathrm{C}_{33} \mathrm{H}_{34} \mathrm{~N}_{10} \mathrm{O}_{2} \\
(602)\end{array}$ & $\begin{array}{l}65.76 \\
65.75\end{array}$ & $\begin{array}{l}5.69 \\
5.68\end{array}$ & $\begin{array}{l}23.24 \\
23.27\end{array}$ \\
\hline $4 f$ & 149-151 & Ethanol & 72 & $\begin{array}{c}\mathrm{C}_{32} \mathrm{H}_{32} \mathrm{~N}_{10} \mathrm{O}_{3} \\
(604)\end{array}$ & $\begin{array}{l}63.56 \\
63.57\end{array}$ & $\begin{array}{l}5.33 \\
5.34\end{array}$ & $\begin{array}{l}23.16 \\
23.14\end{array}$ \\
\hline $4 g$ & $128-129$ & Ethanol & 68 & $\begin{array}{c}\mathrm{C}_{33} \mathrm{H}_{34} \mathrm{~N}_{10} \mathrm{O}_{3} \\
(618)\end{array}$ & $\begin{array}{l}64.06 \\
64.04\end{array}$ & $\begin{array}{l}5.54 \\
5.55\end{array}$ & $\begin{array}{l}22.64 \\
22.65 \\
\end{array}$ \\
\hline
\end{tabular}

$48 \mathrm{~h}$ old cultures $\left(100 \mu \mathrm{L}, 10^{4} \mathrm{cfu}\right)$ and spread evenly on the plate. After $20 \mathrm{~min}$, the wells were filled with different concentrations of samples. The control wells were filled with amphotericin. The sample preparation was done as $20 \mathrm{mg}$ sample dissolved in $1 \mathrm{~mL}$ of solvent (DMSO). The stock sample concentration was $20 \mathrm{mg} / \mathrm{mL}$. All the plates were incubated at $27^{\circ} \mathrm{C}$ for $48 \mathrm{~h}$, and the diameter of the inhibition zones was noted, and MIC values are presented in Table 2.

\section{Results and Discussion}

The facile synthesis of 2-[4-(1-acetyl-5-aryl-4,5-dihydro$1 H$-pyrazol-3-yl)-phenyl]-4-amino-5-methyl-2,4-dihydro-

[1,2,4]-triazol-3-one from 3-[4-(5-aryl-4,5-dihydro- $1 \mathrm{H}$ pyrazolin-3-yl)-phenyl] sydnone by two successive ring conversions has been reported from our laboratory [4]. We thought of exploiting the synthetic utility of potential amino group in these compounds. The amino group was 
TABLE 2: Spectral data of synthesized compounds.

\begin{tabular}{|c|c|c|c|}
\hline Comp. & IR $\mathrm{cm}^{-1}$ & ${ }^{1} \mathrm{H}-\mathrm{NMR} \delta \mathrm{ppm}$ & MS $m / e$ \\
\hline $2 a$ & $\begin{array}{c}3449-3348(\mathrm{NH}) \\
1709 \text { and } 1657 \\
(\mathrm{C}=\mathrm{O}), 1603(\mathrm{C}=\mathrm{N})\end{array}$ & $\begin{array}{l}2.20\left(s, 3 \mathrm{H} \text {, acetyl } \mathrm{CH}_{3}\right), 2.45\left(s, 3 \mathrm{H}, \mathrm{CH}_{3}\right), 3.67(\mathrm{dd}, 1 \mathrm{H}, \\
\left.\left[\mathrm{H}_{\mathrm{A}}\right] \mathrm{CH}_{2}, J=10.12 \mathrm{~Hz}\right), 4.25\left(\mathrm{dd}, 1 \mathrm{H},\left[\mathrm{H}_{\mathrm{B}}\right] \mathrm{CH}_{2}, J=\right. \\
12.25 \mathrm{~Hz}), 4.89\left(m, 1 \mathrm{H},\left[\mathrm{H}_{\mathrm{X}}\right] \mathrm{CH}, J_{\mathrm{XA}}=4 \mathrm{~Hz}, J_{\mathrm{XB}}=7 \mathrm{~Hz}\right), \\
5.93\left(s, 2 \mathrm{H}, \mathrm{NH}_{2}\right), 6.61-8.64(m, 13 \mathrm{H}, \mathrm{Ar}-\mathrm{H}), 9.99(s, 1 \mathrm{H}, \\
\mathrm{N}=\mathrm{CH})\end{array}$ & 479 \\
\hline $2 b$ & $\begin{array}{c}3450-3348(\mathrm{NH}) \\
1710,1654(\mathrm{C}=\mathrm{O}) \\
1605(\mathrm{C}=\mathrm{N})\end{array}$ & $\begin{array}{l}2.24\left(s, 3 \mathrm{H} \text {, acetyl } \mathrm{CH}_{3}\right), 2.40\left(s, 3 \mathrm{H}, \mathrm{CH}_{3}\right), 3.70(\mathrm{dd}, 1 \mathrm{H}, \\
\left.\left[\mathrm{H}_{\mathrm{A}}\right] \mathrm{CH}_{2}, J=13.05 \mathrm{~Hz}\right), 4.23\left(\mathrm{dd}, 1 \mathrm{H},\left[\mathrm{H}_{\mathrm{B}}\right] \mathrm{CH}_{2}, J=\right. \\
12.05 \mathrm{~Hz}), 4.90\left(m, 1 \mathrm{H},\left[\mathrm{H}_{\mathrm{X}}\right] \mathrm{CH}, J_{\mathrm{XA}}=4.80 \mathrm{~Hz}, J_{\mathrm{XB}}=\right. \\
\text { 8.43 Hz), 7.21-8.67 }(m, 12 \mathrm{H}, \mathrm{Ar}-\mathrm{H}), 9.60\left(s, 2 \mathrm{H}, \mathrm{NH}_{2}, \mathrm{D}_{2} \mathrm{O}\right. \\
\text { exchangeable), } 9.109(s, 1 \mathrm{H}, \mathrm{N}=\mathrm{CH})\end{array}$ & $513(\mathrm{M}+), 515(\mathrm{M}+2)$ \\
\hline $2 c$ & $\begin{array}{c}3444-3339(\mathrm{NH}) \\
1705 \text { and } 1650 \\
(\mathrm{C}=\mathrm{O}), 1600 \\
(\mathrm{C}=\mathrm{N})\end{array}$ & $\begin{array}{l}2.20\left(s, 3 \mathrm{H}, \text { acetyl } \mathrm{CH}_{3}\right), 2.43\left(s, 3 \mathrm{H}, \mathrm{CH}_{3}\right), 3.68(\mathrm{dd}, 1 \mathrm{H}, \\
\left.\left[\mathrm{H}_{\mathrm{A}}\right] \mathrm{CH}_{2}, J=11.05 \mathrm{~Hz}\right), 4.20\left(\mathrm{dd}, 1 \mathrm{H},\left[\mathrm{H}_{\mathrm{B}}\right] \mathrm{CH}_{2}, J=\right. \\
13.05 \mathrm{~Hz}), 4.2\left(m, 1 \mathrm{H},\left[\mathrm{H}_{\mathrm{X}}\right] \mathrm{CH}, J_{\mathrm{XA}}=4.45 \mathrm{~Hz}, J_{\mathrm{XB}}=\right. \\
7.75 \mathrm{~Hz}), 7.25-8.70(m, 12 \mathrm{H}, \mathrm{Ar}-\mathrm{H}), 9.55\left(s, 2 \mathrm{H}, \mathrm{NH}_{2}, \mathrm{D}_{2} \mathrm{O}\right. \\
\text { exchangeable }), 9.68(s, 1 \mathrm{H}, \mathrm{N}=\mathrm{CH})\end{array}$ & $513(\mathrm{M}+), 515(\mathrm{M}+2)$ \\
\hline $2 d$ & $\begin{array}{c}3434-3324(\mathrm{NH}) \\
1701,1652(\mathrm{C}=\mathrm{O}) \\
1604(\mathrm{C}=\mathrm{N})\end{array}$ & $\begin{array}{l}2.22\left(s, 3 \mathrm{H}, \text { acetyl } \mathrm{CH}_{3}\right), 2.45\left(s, 3 \mathrm{H}, \mathrm{CH}_{3}\right), 3.62(\mathrm{dd}, 1 \mathrm{H}, \\
\left.\left[\mathrm{H}_{\mathrm{A}}\right] \mathrm{CH}_{2}, J=12.03 \mathrm{~Hz}\right), 4.15\left(\mathrm{dd}, 1 \mathrm{H},\left[\mathrm{H}_{\mathrm{B}}\right] \mathrm{CH}_{2}, J=\right. \\
11.1 \mathrm{~Hz}), 4.89\left(m, 1 \mathrm{H},\left[\mathrm{H}_{\mathrm{X}}\right] \mathrm{CH}, J_{\mathrm{XA}}=7 \mathrm{~Hz}, J_{\mathrm{XB}}=4 \mathrm{~Hz}\right), \\
7.15-8.68(m, 12 \mathrm{H}, \mathrm{Ar}-\mathrm{H}), 9.45\left(s, 2 \mathrm{H}, \mathrm{NH}_{2}, \mathrm{D}_{2} \mathrm{O}\right. \\
\text { exchangeable }), 9.70(s, 1 \mathrm{H}, \mathrm{N}=\mathrm{CH})\end{array}$ & $513(\mathrm{M}+), 515(\mathrm{M}+2)$ \\
\hline $2 e$ & $\begin{array}{c}3455-3335(\mathrm{NH}) \\
1705,1654(\mathrm{C}=\mathrm{O}) \\
1600(\mathrm{C}=\mathrm{N})\end{array}$ & $\begin{array}{l}2.25\left(s, 3 \mathrm{H}, \text { acetyl } \mathrm{CH}_{3}\right), 2.30\left(s, 3 \mathrm{H}, \mathrm{CH}_{3}\right), 2.50(s, 3 \mathrm{H}, \\
\left.\mathrm{CH}_{3}\right), 3.60\left(\mathrm{dd}, 1 \mathrm{H},\left[\mathrm{H}_{\mathrm{A}}\right] \mathrm{CH}_{2}, J=11.80 \mathrm{~Hz}\right), 4.20(\mathrm{dd}, 1 \mathrm{H}, \\
\left.\left[\mathrm{H}_{\mathrm{B}}\right] \mathrm{CH}_{2}, J=11.1 \mathrm{~Hz}\right), 4.89\left(m, 1 \mathrm{H},\left[\mathrm{H}_{\mathrm{X}}\right] \mathrm{CH}, J_{\mathrm{XA}}=7 \mathrm{~Hz},\right. \\
\left.J_{\mathrm{XB}}=4 \mathrm{~Hz}\right), 6.50-7.108(m, 12 \mathrm{H}, \mathrm{Ar}-\mathrm{H}), 7.1\left(s, 2 \mathrm{H}, \mathrm{NH}_{2}, \mathrm{D}_{2} \mathrm{O}\right. \\
\text { exchangeable }), 8.11(s, 1 \mathrm{H}, \mathrm{N}=\mathrm{CH})\end{array}$ & 493 \\
\hline $2 f$ & $\begin{array}{c}3460(\mathrm{OH}) \\
3449-3348(\mathrm{NH}) \\
1712,1657(\mathrm{C}=\mathrm{O}) \\
1603(\mathrm{C}=\mathrm{N})\end{array}$ & $\begin{array}{l}2.22\left(s, 3 \mathrm{H}, \text { acetyl } \mathrm{CH}_{3}\right), 2.47\left(s, 3 \mathrm{H}, \mathrm{CH}_{3}\right), 3.65(\mathrm{dd}, 1 \mathrm{H}, \\
\left.\left[\mathrm{H}_{\mathrm{A}}\right] \mathrm{CH}_{2}, J=12.10 \mathrm{~Hz}\right), 4.25\left(\mathrm{dd}, 1 \mathrm{H},\left[\mathrm{H}_{\mathrm{B}}\right] \mathrm{CH}_{2}, J=\right. \\
12.06 \mathrm{~Hz}), 4.109\left(\mathrm{~m}, 1 \mathrm{H},\left[\mathrm{H}_{\mathrm{X}}\right] \mathrm{CH}, J_{\mathrm{XA}}=3.32 \mathrm{~Hz}, J_{\mathrm{XB}}=\right. \\
4.32 \mathrm{~Hz}), 5.15\left(s, 1 \mathrm{H}, \mathrm{OH}, \mathrm{D}_{2} \mathrm{O} \text { exchangeable }\right), 7.25-8.65(m, \\
12 \mathrm{H}, \mathrm{Ar}-\mathrm{H}), 9.50\left(s, 2 \mathrm{H}, \mathrm{NH}_{2}, \mathrm{D}_{2} \mathrm{O} \text { exchangeable }\right), 9.69(s, \\
1 \mathrm{H}, \mathrm{N}=\mathrm{CH})\end{array}$ & 495 \\
\hline $2 \mathrm{~g}$ & $\begin{array}{c}3439-3325(\mathrm{NH}) \\
1715,1654(\mathrm{C}=\mathrm{O}) \\
1605(\mathrm{C}=\mathrm{N})\end{array}$ & $\begin{array}{l}2.30\left(s, 3 \mathrm{H}, \text { acetyl } \mathrm{CH}_{3}\right), 3.72\left(s, 3 \mathrm{H},-\mathrm{OCH}_{3}\right), 2.47(s, 3 \mathrm{H}, \\
\left.\mathrm{CH}_{3}\right), 3.65\left(\mathrm{dd}, 1 \mathrm{H},\left[\mathrm{H}_{\mathrm{A}}\right] \mathrm{CH}_{2}, J=10.10 \mathrm{~Hz}\right), 4.26(\mathrm{dd}, 1 \mathrm{H}, \\
\left.\left[\mathrm{H}_{\mathrm{B}}\right] \mathrm{CH}_{2}, J=12.06 \mathrm{~Hz}\right), 4.79\left(m, 1 \mathrm{H},\left[\mathrm{H}_{\mathrm{X}}\right] \mathrm{CH}, J_{\mathrm{XA}}=4 \mathrm{~Hz},\right. \\
\left.J_{\mathrm{XB}}=7 \mathrm{~Hz}\right), 6.50-7.50(m, 12 \mathrm{H}, \mathrm{Ar}-\mathrm{H}), 8.23\left(s, 2 \mathrm{H}, \mathrm{NH}_{2},\right. \\
\left.\mathrm{D}_{2} \mathrm{O} \text { exchangeable }\right), 8.55(s, 1 \mathrm{H}, \mathrm{N}=\mathrm{CH})\end{array}$ & 586 \\
\hline $3 \mathbf{a}$ & $\begin{array}{c}1711,1658,1605 \\
(\mathrm{C}=\mathrm{O}), 1519(\mathrm{C}=\mathrm{N})\end{array}$ & $\begin{array}{l}1.97\left(s, 3 \mathrm{H}, \text { acetyl } \mathrm{CH}_{3}\right), 2.37\left(s, 6 \mathrm{H}, \mathrm{CH}_{3}\right), 2.46(s, 3 \mathrm{H}, \\
\left.\mathrm{C}_{5}-\mathrm{CH}_{3}\right), 3.31\left(\mathrm{dd}, 1 \mathrm{H},\left[\mathrm{H}_{\mathrm{A}}\right] \mathrm{CH}_{2}, J=11.05 \mathrm{~Hz}\right), 3.69(\mathrm{dd}, \\
\left.1 \mathrm{H},\left[\mathrm{H}_{\mathrm{B}}\right] \mathrm{CH}_{2}, J=12.06 \mathrm{~Hz}\right), 4.63\left(m, 1 \mathrm{H},\left[\mathrm{H}_{\mathrm{X}}\right] \mathrm{CH}, J_{\mathrm{XA}}=\right. \\
\left.4.55 \mathrm{~Hz}, J_{\mathrm{XB}}=8.43 \mathrm{~Hz}\right), 5.53\left(s, 1 \mathrm{H}, \mathrm{NH}\left(\mathrm{D}_{2} \mathrm{O}\right.\right. \\
\text { exchangeable })), 7.19-8.24(m, 13 \mathrm{H}, \mathrm{Ar}-\mathrm{H}), 9.99(s, 1 \mathrm{H}, \\
\mathrm{N}=\mathrm{CH})\end{array}$ & 590 \\
\hline $3 b$ & $\begin{array}{c}3455(\mathrm{NH}), 1710 \\
1658,1604(\mathrm{C}=\mathrm{O}) \\
1532(\mathrm{C}=\mathrm{N})\end{array}$ & $\begin{array}{l}1.72\left(s, 3 \mathrm{H} \text {, acetyl } \mathrm{CH}_{3}\right), 2.30\left(s, 6 \mathrm{H}, \mathrm{CH}_{3}\right), 2.40(s, 3 \mathrm{H}, \\
\left.\mathrm{C}_{5}-\mathrm{CH}_{3}\right), 3.20-3.25\left(\mathrm{dd}, 1 \mathrm{H},\left[\mathrm{H}_{\mathrm{A}}\right] \mathrm{CH}_{2}, J=12.03 \mathrm{~Hz}\right), 3.71 \\
\left(\mathrm{dd}, 1 \mathrm{H},\left[\mathrm{H}_{\mathrm{B}}\right] \mathrm{CH}_{2}, J=12.05 \mathrm{~Hz}\right), 4.79\left(m, 1 \mathrm{H},\left[\mathrm{H}_{\mathrm{X}}\right] \mathrm{CH}, J_{\mathrm{XA}}\right. \\
\left.=3.34 \mathrm{~Hz}, J_{\mathrm{XB}}=10.11 \mathrm{~Hz}\right), 5.55\left(s, 1 \mathrm{H}, \mathrm{NH}\left(\mathrm{D}_{2} \mathrm{O}\right.\right. \\
\text { exchangeable })), 7.25-8.30(m, 12 \mathrm{H}, \mathrm{Ar}-\mathrm{H}), 8.64(s, 1 \mathrm{H}, \\
\mathrm{N}=\mathrm{CH})\end{array}$ & $624(\mathrm{M}+), 626(\mathrm{M}+2)$ \\
\hline $3 c$ & $\begin{array}{c}3445(\mathrm{NH}), 1715 \\
1656,1600(\mathrm{C}=\mathrm{O}) \\
1524(\mathrm{C}=\mathrm{N})\end{array}$ & $\begin{array}{l}1.69\left(s, 3 \mathrm{H} \text {, acetyl } \mathrm{CH}_{3}\right), 2.30\left(s, 6 \mathrm{H}, \mathrm{CH}_{3}\right), 2.45(s, 3 \mathrm{H}, \\
\left.\mathrm{C}_{5}-\mathrm{CH}_{3}\right), 3.24-3.27\left(\mathrm{dd}, 1 \mathrm{H},\left[\mathrm{H}_{\mathrm{A}}\right] \mathrm{CH}_{2}, J=12.00 \mathrm{~Hz}\right), 3.71 \\
\left(\mathrm{dd}, 1 \mathrm{H},\left[\mathrm{H}_{\mathrm{B}}\right] \mathrm{CH}_{2}, J=12.05 \mathrm{~Hz}\right), 4.79\left(m, 1 \mathrm{H},\left[\mathrm{H}_{\mathrm{X}}\right] \mathrm{CH}, J_{\mathrm{XA}}\right. \\
\left.=7 \mathrm{~Hz}, J_{\mathrm{XB}}=4 \mathrm{~Hz}\right), 5.58\left(s, 1 \mathrm{H}, \mathrm{NH}\left(\mathrm{D}_{2} \mathrm{O} \text { exchangeable }\right)\right) \\
\text { 6.50-7.108 }(m, 13 \mathrm{H}, \mathrm{Ar}-\mathrm{H}), 8.00(s, 1 \mathrm{H}, \mathrm{N}=\mathrm{CH})\end{array}$ & $624(\mathrm{M}+), 626(\mathrm{M}+2)$ \\
\hline $3 d$ & $\begin{array}{c}3455(\mathrm{NH}), 1708 \\
1654,1604(\mathrm{C}=\mathrm{O}) \\
1530(\mathrm{C}=\mathrm{N})\end{array}$ & $\begin{array}{l}1.75\left(s, 3 \mathrm{H} \text {, acetyl } \mathrm{CH}_{3}\right), 2.35\left(s, 6 \mathrm{H}, \mathrm{CH}_{3}\right), 2.49(s, 3 \mathrm{H}, \\
\left.\mathrm{C}_{5}-\mathrm{CH}_{3}\right), 3.27-3.29\left(\mathrm{dd}, 1 \mathrm{H},\left[\mathrm{H}_{\mathrm{A}}\right] \mathrm{CH}_{2}, J=11.05 \mathrm{~Hz}\right), 3.75 \\
\left(\mathrm{dd}, 1 \mathrm{H},\left[\mathrm{H}_{\mathrm{B}}\right] \mathrm{CH}_{2}, J=12.07 \mathrm{~Hz}\right), 4.80\left(m, 1 \mathrm{H},\left[\mathrm{H}_{\mathrm{X}}\right] \mathrm{CH}, J_{\mathrm{XA}}\right. \\
\left.=7.73 \mathrm{~Hz}, J_{\mathrm{XB}}=4.47 \mathrm{~Hz}\right), 5.57\left(s, 1 \mathrm{H}, \mathrm{NH}\left(\mathrm{D}_{2} \mathrm{O}\right.\right. \\
\text { exchangeable })), 6.55-7.75(m, 13 \mathrm{H}, \mathrm{Ar}-\mathrm{H}), 8.13(s, 1 \mathrm{H}, \\
\mathrm{N}=\mathrm{CH})\end{array}$ & $624(\mathrm{M}+), 626(\mathrm{M}+2)$ \\
\hline
\end{tabular}


TABLe 2: Continued.

\begin{tabular}{|c|c|c|c|c|}
\hline Comp. & $\mathrm{IR} \mathrm{cm}^{-1}$ & ${ }^{1} \mathrm{H}-\mathrm{NMR} \delta \mathrm{ppm}$ & ${ }^{13} \mathrm{C}-\mathrm{NMR}$ & $\mathrm{MS} m / e$ \\
\hline $3 e$ & $\begin{array}{c}3455(\mathrm{NH}), 1710, \\
1658,1604(\mathrm{C}=\mathrm{O}), \\
1532(\mathrm{C}=\mathrm{N})\end{array}$ & $\begin{array}{l}1.68\left(s, 3 \mathrm{H}, \text { acetyl } \mathrm{CH}_{3}\right), 2.36\left(s, 6 \mathrm{H}, \mathrm{CH}_{3}\right), 2.40(s, 3 \mathrm{H}, \\
\left.\mathrm{C}_{5}-\mathrm{CH}_{3}\right), 2.54\left(s, 3 \mathrm{H}, \mathrm{CH}_{3}\right), 3.25-3.28\left(\mathrm{dd}, 1 \mathrm{H},\left[\mathrm{H}_{\mathrm{A}}\right] \mathrm{CH}_{2}, J\right. \\
=13.00 \mathrm{~Hz}), 3.107\left(\mathrm{dd}, 1 \mathrm{H},\left[\mathrm{H}_{\mathrm{B}}\right] \mathrm{CH}_{2}, J=12.07 \mathrm{~Hz}\right), 4.89(m, \\
\left.1 \mathrm{H},\left[\mathrm{H}_{\mathrm{X}}\right] \mathrm{CH}, J_{\mathrm{XA}}=5.54 \mathrm{~Hz}, J_{\mathrm{XB}}=8.44 \mathrm{~Hz}\right), 5.56(s, 1 \mathrm{H}, \mathrm{NH} \\
\left.\left(\mathrm{D}_{2} \mathrm{O} \text { exchangeable }\right)\right), 6.50-7.109(m, 13 \mathrm{H}, \mathrm{Ar}-\mathrm{H}), 8.15(s, 1 \mathrm{H} \text {, } \\
\mathrm{N}=\mathrm{CH})\end{array}$ & & 604 \\
\hline $3 f$ & $\begin{array}{c}3550(\mathrm{OH}), 3457 \\
(\mathrm{NH}), 1713,1658 \\
1604(\mathrm{C}=\mathrm{O}), 1530 \\
(\mathrm{C}=\mathrm{N})\end{array}$ & $\begin{array}{l}1.72\left(s, 3 \mathrm{H} \text {, acetyl } \mathrm{CH}_{3}\right), 2.37\left(s, 6 \mathrm{H}, \mathrm{CH}_{3}\right), 2.45(s, 3 \mathrm{H}, \\
\left.\mathrm{C}_{5}-\mathrm{CH}_{3}\right), 3.14-3.31\left(\mathrm{dd}, 1 \mathrm{H},\left[\mathrm{H}_{\mathrm{A}}\right] \mathrm{CH}_{2}, J=10.05 \mathrm{~Hz}\right), 3.72 \\
\left(\mathrm{dd}, 1 \mathrm{H},\left[\mathrm{H}_{\mathrm{B}}\right] \mathrm{CH}_{2}, J=13.06 \mathrm{~Hz}\right), 4.75\left(m, 1 \mathrm{H},\left[\mathrm{H}_{\mathrm{X}}\right] \mathrm{CH}, J_{\mathrm{XA}}\right. \\
\left.=4.43 \mathrm{~Hz}, J_{\mathrm{XB}}=8.88 \mathrm{~Hz}\right), 5.53\left(s, 1 \mathrm{H}, \mathrm{NH}\left(\mathrm{D}_{2} \mathrm{O}\right.\right. \\
\text { exchangeable })), 5.60(s, 1 \mathrm{H}, \mathrm{OH})\left(\mathrm{D}_{2} \mathrm{O} \text { exchangeable }\right), \\
7.20-8.25(m, 13 \mathrm{H}, \mathrm{Ar}-\mathrm{H}), 9.00(s, 1 \mathrm{H}, \mathrm{N}=\mathrm{CH})\end{array}$ & & 606 \\
\hline $3 g$ & $\begin{array}{c}3455(\mathrm{NH}), 1708, \\
1654,1604(\mathrm{C}=\mathrm{O}), \\
1532(\mathrm{C}=\mathrm{N})\end{array}$ & $\begin{array}{l}1.75\left(s, 3 \mathrm{H}, \text { acetyl } \mathrm{CH}_{3}\right), 2.35\left(s, 6 \mathrm{H}, \mathrm{CH}_{3}\right), 2.49(s, 3 \mathrm{H}, \\
\left.\mathrm{C}_{5}-\mathrm{CH}_{3}\right), 3.75\left(s, 3 \mathrm{H},-\mathrm{OCH}_{3}\right), 3.27-3.29\left(\mathrm{dd}, 1 \mathrm{H},\left[\mathrm{H}_{\mathrm{A}}\right]\right. \\
\left.\mathrm{CH}_{2}, J=12.05 \mathrm{~Hz}\right), 3.75\left(\mathrm{dd}, 1 \mathrm{H},\left[\mathrm{H}_{\mathrm{B}}\right] \mathrm{CH}_{2}, J=12.07 \mathrm{~Hz}\right), \\
4.80\left(m, 1 \mathrm{H},\left[\mathrm{H}_{\mathrm{X}}\right] \mathrm{CH}, J_{\mathrm{XA}}=4.80 \mathrm{~Hz}, J_{\mathrm{XB}}=8.48 \mathrm{~Hz}\right), 5.55(s, \\
\left.1 \mathrm{H}, \mathrm{NH}\left(\mathrm{D}_{2} \mathrm{O} \text { exchangeable }\right)\right), 6.55-7.75(m, 13 \mathrm{H}, \mathrm{Ar}-\mathrm{H}), \\
8.15(s, 1 \mathrm{H}, \mathrm{N}=\mathrm{CH})\end{array}$ & & 620 \\
\hline $4 a$ & $\begin{array}{c}3426(\mathrm{NH}), 1704 \\
1617(\mathrm{C}=\mathrm{O}), 1519 \\
(\mathrm{C}=\mathrm{N})\end{array}$ & $\begin{array}{l}1.18(s, 1 \mathrm{H}, \mathrm{NH}), 1.58\left(s, 3 \mathrm{H}, \text { acetyl } \mathrm{CH}_{3}\right), 2.29\left(s, 3 \mathrm{H}, \mathrm{CH}_{3}\right) \\
2.36\left(s, 3 \mathrm{H}, \mathrm{CH}_{3}\right), 2.45\left(s, 3 \mathrm{H}, \mathrm{C}_{5}-\mathrm{CH}_{3}\right), 3.63\left(\mathrm{dd}, 1 \mathrm{H},\left[\mathrm{H}_{\mathrm{A}}\right]\right. \\
\left.\mathrm{CH}_{2}, J=11.03 \mathrm{~Hz}\right), 3.73\left(\mathrm{dd}, 1 \mathrm{H},\left[\mathrm{H}_{\mathrm{B}}\right] \mathrm{CH}_{2}, J=12.00 \mathrm{~Hz}\right), \\
4.24\left(s, 6 \mathrm{H}, \mathrm{CH}_{3}\right), 5.51\left(m, 1 \mathrm{H},\left[\mathrm{H}_{\mathrm{X}}\right] \mathrm{CH}, J_{\mathrm{XA}}=4.40 \mathrm{~Hz}, J_{\mathrm{XB}}\right. \\
=11.00 \mathrm{~Hz}), 7.19-7.96(m, 13 \mathrm{H}, \mathrm{Ar}-\mathrm{H}), 7.99(s, 1 \mathrm{H}, \mathrm{C}=\mathrm{NH})\end{array}$ & $\begin{array}{l}\text { 10.73, 12.63, 21.95, 44.51, } \\
60.57,107.83,119.80,126.39 \\
129.60,129.06,130.12 \\
130.82,139.46,142.53 \\
151.29,154.32,155.87,169.21 \\
\end{array}$ & 586 \\
\hline $4 b$ & $\begin{array}{c}3430(\mathrm{NH}), 1707 \\
1620(\mathrm{C}=\mathrm{O}), 1594 \\
(\mathrm{C}=\mathrm{N})\end{array}$ & $\begin{array}{l}\text { 1.16 }(s, 1 \mathrm{H}, \mathrm{NH}), 2.00\left(s, 3 \mathrm{H} \text {, acetyl } \mathrm{CH}_{3}\right), 2.31\left(s, 3 \mathrm{H}, \mathrm{CH}_{3}\right) \\
2.40\left(s, 3 \mathrm{H}, \mathrm{CH}_{3}\right), 2.50\left(s, 3 \mathrm{H}, \mathrm{C}_{5}-\mathrm{CH}_{3}\right), 3.70\left(\mathrm{dd}, 1 \mathrm{H},\left[\mathrm{H}_{\mathrm{A}}\right]\right. \\
\left.\mathrm{CH}_{2}, J=12.03 \mathrm{~Hz}\right), 3.107\left(\mathrm{dd}, 1 \mathrm{H},\left[\mathrm{H}_{\mathrm{B}}\right] \mathrm{CH}_{2}, J=11.00 \mathrm{~Hz}\right) \\
4.30\left(s, 6 \mathrm{H}, \mathrm{CH}_{3}\right), 5.55\left(m, 1 \mathrm{H},\left[\mathrm{H}_{\mathrm{X}}\right] \mathrm{CH}, J_{\mathrm{XA}}=4.80 \mathrm{~Hz}, J_{\mathrm{XB}}\right. \\
=11.42 \mathrm{~Hz}), 7.25-8.00(m, 12 \mathrm{H}, \mathrm{Ar}-\mathrm{H}), 8.05(s, 1 \mathrm{H}, \mathrm{C}=\mathrm{NH})\end{array}$ & $\begin{array}{l}\text { 10.56, 11.72, 21.44, 45.81, } \\
60.51,107.69,119.03,127.73 \\
29.72,130.01,131.12,131.82 \\
139.92,142.35,150.58 \\
154.43,155.62,169.39\end{array}$ & $622(\mathrm{M}+), 624(\mathrm{M}+2)$ \\
\hline $4 c$ & $\begin{array}{c}3420(\mathrm{NH}), 1710 \\
1625(\mathrm{C}=\mathrm{O}), 1593 \\
(\mathrm{C}=\mathrm{N})\end{array}$ & $\begin{array}{l}1.19(s, 1 \mathrm{H}, \mathrm{NH}), 2.05\left(s, 3 \mathrm{H} \text {, acetyl } \mathrm{CH}_{3}\right), 2.34\left(s, 3 \mathrm{H}, \mathrm{CH}_{3}\right), \\
2.43\left(s, 3 \mathrm{H}, \mathrm{CH}_{3}\right), 2.52\left(s, 3 \mathrm{H}, \mathrm{C}_{5}-\mathrm{CH}_{3}\right), 3.71\left(\mathrm{dd}, 1 \mathrm{H},\left[\mathrm{H}_{\mathrm{A}}\right]\right. \\
\left.\mathrm{CH}_{2}, J=14.03 \mathrm{~Hz}\right), 3.107\left(\mathrm{dd}, 1 \mathrm{H},\left[\mathrm{H}_{\mathrm{B}}\right] \mathrm{CH}_{2}, J=12.05 \mathrm{~Hz}\right), \\
4.30\left(s, 6 \mathrm{H}, \mathrm{CH}_{3}\right), 5.30\left(m, 1 \mathrm{H},\left[\mathrm{H}_{\mathrm{X}}\right] \mathrm{CH}, J_{\mathrm{XA}}=4.5 \mathrm{~Hz}, J_{\mathrm{XB}}=\right. \\
11.00 \mathrm{~Hz}), 7.30-7.12(m, 12 \mathrm{H}, \mathrm{Ar}-\mathrm{H}) 8.00(s, 1 \mathrm{H}, \mathrm{C}=\mathrm{NH})\end{array}$ & $\begin{array}{l}9.13,11.79,21.69,42.11 \\
59.48,105.39,117.51,125.39 \\
127.16,127.76,128.23,128.62 \\
137.03,142.35,150.48 \\
153.32,154.69,167.36\end{array}$ & $622(\mathrm{M}+), 624(\mathrm{M}+2)$ \\
\hline $4 d$ & $\begin{array}{c}3435(\mathrm{NH}), 1710 \\
1627(\mathrm{C}=\mathrm{O}), 1560 \\
(\mathrm{C}=\mathrm{N})\end{array}$ & $\begin{array}{l}1.16(s, 1 \mathrm{H}, \mathrm{NH}), 2.07\left(s, 3 \mathrm{H}, \text { acetyl } \mathrm{CH}_{3}\right), 2.32\left(s, 3 \mathrm{H}, \mathrm{CH}_{3}\right) \\
2.42\left(s, 3 \mathrm{H}, \mathrm{CH}_{3}\right), 2.51\left(s, 3 \mathrm{H}, \mathrm{C}_{5}-\mathrm{CH}_{3}\right), 3.109\left(\mathrm{dd}, 1 \mathrm{H},\left[\mathrm{H}_{\mathrm{A}}\right]\right. \\
\left.\mathrm{CH}_{2}, J=11.03 \mathrm{~Hz}\right), 3.80\left(\mathrm{dd}, 1 \mathrm{H},\left[\mathrm{H}_{\mathrm{B}}\right] \mathrm{CH}_{2}, J=12.00 \mathrm{~Hz}\right) \\
4.35\left(s, 6 \mathrm{H}, \mathrm{CH}_{3}\right), 5.56\left(m, 1 \mathrm{H},\left[\mathrm{H}_{\mathrm{X}}\right] \mathrm{CH}, J_{\mathrm{XA}}=3.33 \mathrm{~Hz}, J_{\mathrm{XB}}\right. \\
=9.89 \mathrm{~Hz}), 7.24-8.05(m, 12 \mathrm{H}, \mathrm{Ar}-\mathrm{H}) 8.10(s, 1 \mathrm{H}, \mathrm{C}=\mathrm{NH})\end{array}$ & $\begin{array}{l}8.79,11.63,22.41,41.14 \\
58.44,106.43,118.51,124.82 \\
126.82,127.62,128.88 \\
128.96,142.71,151.51,153.53 \\
154.46,167.91\end{array}$ & $622(\mathrm{M}+), 624(\mathrm{M}+2)$ \\
\hline $4 e$ & $\begin{array}{c}3420(\mathrm{NH}), 1710 \\
1625(\mathrm{C}=\mathrm{O}), 1593 \\
(\mathrm{C}=\mathrm{N})\end{array}$ & $\begin{array}{l}1.19(s, 1 \mathrm{H}, \mathrm{NH}), 2.05\left(s, 3 \mathrm{H}, \text { acetyl } \mathrm{CH}_{3}\right), 2.30\left(s, 3 \mathrm{H}, \mathrm{CH}_{3}\right) \\
2.43\left(s, 3 \mathrm{H}, \mathrm{CH}_{3}\right), 2.47\left(s, 3 \mathrm{H}, \mathrm{C}_{5}-\mathrm{CH}_{3}\right), 3.71\left(\mathrm{dd}, 1 \mathrm{H},\left[\mathrm{H}_{\mathrm{A}}\right]\right. \\
\left.\mathrm{CH}_{2}, J=14.03 \mathrm{~Hz}\right), 3.107\left(\mathrm{dd}, 1 \mathrm{H},\left[\mathrm{H}_{\mathrm{B}}\right] \mathrm{CH}_{2}, J=13.05 \mathrm{~Hz}\right) \\
4.30\left(s, 6 \mathrm{H}, \mathrm{CH}_{3}\right), 5.30\left(m, 1 \mathrm{H},\left[\mathrm{H}_{\mathrm{X}}\right] \mathrm{CH}, J_{\mathrm{XA}}=4.00 \mathrm{~Hz}, J_{\mathrm{XB}}\right. \\
=9 \mathrm{~Hz}), 7.30-7.92(m, 12 \mathrm{H}, \mathrm{Ar}-\mathrm{H}), 7.99(s, 1 \mathrm{H}, \mathrm{C}=\mathrm{NH})\end{array}$ & $\begin{array}{l}9.12,11.81,22.59,41.12,58.91 \\
106.34,118.51,124.32,126.93, \\
127.71,128.42,128.69,143.01, \\
151.01,153.35,154.79,167.66\end{array}$ & 602 \\
\hline $4 f$ & $\begin{array}{c}3510(\mathrm{OH}), 3420 \\
(\mathrm{NH}), 1715,1623 \\
(\mathrm{C}=\mathrm{O}), 152(\mathrm{C}=\mathrm{N})\end{array}$ & $\begin{array}{l}1.71(s, 1 \mathrm{H}, \mathrm{NH}), 2.10\left(s, 3 \mathrm{H}, \text { acetyl } \mathrm{CH}_{3}\right), 2.35\left(s, 3 \mathrm{H}, \mathrm{CH}_{3}\right) \\
2.45\left(s, 3 \mathrm{H}, \mathrm{CH}_{3}\right), 2.49\left(s, 3 \mathrm{H}, \mathrm{C}_{5}-\mathrm{CH}_{3}\right), 3.71\left(\mathrm{dd}, 1 \mathrm{H},\left[\mathrm{H}_{\mathrm{A}}\right]\right. \\
\left.\mathrm{CH}_{2}, J=12.05 \mathrm{~Hz}\right), 3.108\left(\mathrm{dd}, 1 \mathrm{H},\left[\mathrm{H}_{\mathrm{B}}\right] \mathrm{CH}_{2}, J=15.05 \mathrm{~Hz}\right), \\
4.35\left(s, 6 \mathrm{H}, \mathrm{CH}_{3}\right), 5.32\left(m, 1 \mathrm{H},\left[\mathrm{H}_{\mathrm{X}}\right] \mathrm{CH}, J_{\mathrm{XA}}=4.43 \mathrm{~Hz}, J_{\mathrm{XB}}\right. \\
=8.50 \mathrm{~Hz}), 5.50(s, 1 \mathrm{H}, \mathrm{OH}), 7.35-7.1(m, 12 \mathrm{H}, \mathrm{Ar}-\mathrm{H}), 8.11(s, \\
1 \mathrm{H}, \mathrm{C}=\mathrm{NH})\end{array}$ & $\begin{array}{l}9.15,11.83,22.58,14.12,59.96 \\
107.39,118.75,125.39,126.83, \\
127.91,128.42,128.84,144.61, \\
151.48,153.84,154.86,168.69\end{array}$ & 604 \\
\hline $4 g$ & $\begin{array}{c}3437(\mathrm{NH}), 1708 \\
1627(\mathrm{C}=\mathrm{O}), 1567 \\
(\mathrm{C}=\mathrm{N})\end{array}$ & $\begin{array}{l}1.67(s, 1 \mathrm{H}, \mathrm{NH}), 2.08\left(s, 3 \mathrm{H} \text {, acetyl } \mathrm{CH}_{3}\right), 2.35\left(s, 3 \mathrm{H}, \mathrm{CH}_{3}\right), \\
2.47\left(s, 3 \mathrm{H}, \mathrm{CH}_{3}\right), 2.52\left(s, 3 \mathrm{H}, \mathrm{C}_{5}-\mathrm{CH}_{3}\right), 3.73(s, 3 \mathrm{H}, \\
\left.\left.-\mathrm{OCH}_{3}\right), 3.80\left(\mathrm{dd}, 1 \mathrm{H}, \mathrm{H}_{\mathrm{A}}\right] \mathrm{CH}_{2}, J=14.03 \mathrm{~Hz}\right), 3.2(\mathrm{dd}, 1 \mathrm{H}, \\
\left.\left[\mathrm{H}_{\mathrm{B}}\right] \mathrm{CH}_{2}, J=10.00 \mathrm{~Hz}\right), 4.37\left(s, 6 \mathrm{H}, \mathrm{CH}_{3}\right), 5.56(m, 1 \mathrm{H}, \\
\left.\left[\mathrm{H}_{\mathrm{X}}\right] \mathrm{CH}, J_{\mathrm{XA}}=4.00 \mathrm{~Hz}, J_{\mathrm{XB}}=11.00 \mathrm{~Hz}\right), 7.25-8.07(m, 12 \mathrm{H}, \\
\mathrm{Ar}-\mathrm{H}) 8.10(s, 1 \mathrm{H}, \mathrm{C}=\mathrm{NH})\end{array}$ & $\begin{array}{l}8.47,12.38,23.82,42.85 \\
59.36,106.28,118.84,126.92 \\
127.84,128.47,129.02 \\
129.96,143.44,151.86 \\
154.95,155.79,169.61\end{array}$ & 618 \\
\hline
\end{tabular}


TABle 3: Molecular Osiris property of compounds $\mathbf{4 a}-\mathbf{g}$.

\begin{tabular}{lcccc}
\hline Entry no. & $c \log P$ & Mol Wt & Drug likeliness & Drug score \\
\hline 4a & 6.08 & 580 & -1.34 & 0.05 \\
4b & 6.69 & 620 & -1.65 & 0.04 \\
4c & 6.69 & 620 & -2.10 & 0.04 \\
4d & 6.69 & 620 & -0.44 & 0.04 \\
4e & 6.40 & 600 & -3.14 & 0.04 \\
4f & 5.109 & 602 & -1.108 & 0.04 \\
4g & 5.4 & 616 & -1.84 & 0.04 \\
\hline
\end{tabular}

unreactive towards reagents like $\alpha$-halogen esters, KCNS, nitrous acid, and so forth, indicating its weak nucleophilic character, which is due to strong electron-withdrawing 1,2,4-triazolin-2-one ring. In an attempt to prepare the azopyrazolobenzylidene derivatives, we thought of using the 4-(4-nitrobenzylideneamino)-2-(4-(1-acetyl-4,5-dihydro5-aryl-1H-pyrazol-3-yl)phenyl)-5-methyl-2H-1,2,4-triazol$3(4 H)$-one $\mathbf{1 a}-\mathbf{g}$ as starting material. The compounds $\mathbf{1 a - g}$ on reduction with $\mathrm{Sn} / \mathrm{HCl}$ gave the compound $\mathbf{2 a}-\mathbf{g}$, and further reaction with sodium nitrite, sodium acetate, and acetylacetone yielded the 2,4-dione 3a-g (Japp-Klingemann reaction). The reaction of compound $3 \mathbf{a}-\mathbf{g}$ with hydrazine hydrate afforded azopyrazolobenzylidene derivatives $\mathbf{4 a -} \mathbf{g}$ (Figure 1). The mechanism of conversion of compounds la-g to $4 \mathbf{a}-\mathbf{g}$ is presented in Figure 2.

The mechanism involves diazotization of compound $2 \mathbf{a}-\mathbf{g}$ to give diazonium salt which on coupling with enolate form of acetylacetone gave diazo compound. Hydrazine hydrate was made to attack two carbonyl groups of the diazo compound nucleophilically, and subsequent dehydration of the formed intermediate gave final compounds $\mathbf{4 a - g}$.

The Schiff base of 2-[4-(1-acetyl-5-nitrophenyl-4,5dihydro-1H-pyrazol-3-yl)-phenyl]-4-amino-5-methyl-2,4dihydro-[1,2,4]-triazol-3-one $\mathbf{l a - g}$ has been utilized as useful precursor for the synthesis of pyrazole derivatives. Exploitation of structure activity relationship (SAR) studies of such combination of heterocycles could lead to the development of congener with more therapeutic index than those of parent compounds. There is a considerable interest in chemotherapeutic activity of triazole and pyrazole derivatives, and hence, interesting pharmacological properties have been claimed. The synthesis of pyrazole built on the para position of phenyl ring attached to sydnone is reported from this laboratory [4]. These observations and the ease with which the compounds having two pyrazole and one 1,2,4-triazole ring encouraged us to explore present work. Though many pyrazole derivatives have been reported, it is for the first time that a molecule having two pyrazoles spaced with 1,2,4-triazole were synthesized starting from $\mathrm{N}$-arylsydnones as synthons.

The IR spectra of intermediate amino compounds 2a$\mathrm{g}$ showed bands for the asymmetric and symmetric stretching vibrations of $\mathrm{NH}_{2}$ in the range of $3455-3434 \mathrm{~cm}^{-1}$ and $3348-3324 \mathrm{~cm}^{-1}$, respectively. The carbonyl group of the 1,2,4-triazolin-2-one ring appeared as a sharp band at $1715-1705 \mathrm{~cm}^{-1}$ and that of acetyl group appeared around
$1657-1650 \mathrm{~cm}^{-1}$. The $\mathrm{C}=\mathrm{N}$ group showed a band at $1600-$ $1653 \mathrm{~cm}^{-1}$. Compound $2 \mathrm{e}$ showed a band at $3455 \mathrm{~cm}^{-1}$ for $\mathrm{OH}$ stretching. The IR spectra of diones $\mathbf{3 a} \mathbf{a}-\mathbf{g}$ showed a broad band at $3455-3439 \mathrm{~cm}^{-1}$ due to NH vibrations. The carbonyl group of the 2,4-dione moiety appeared at $1658-1652 \mathrm{~cm}^{-1}$, while that of the 1,2,4-triazolin-2-one ring appeared at 1715$1710 \mathrm{~cm}^{-1}$. Also, carbonyl of acetyl group appeared around $1600-1604 \mathrm{~cm}^{-1}$. The $\mathrm{C}=\mathrm{N}$ group showed a band around $1519-1532 \mathrm{~cm}^{-1}$. Compound $2 \mathrm{e}$ showed a band at $3550 \mathrm{~cm}^{-1}$ for $\mathrm{OH}$ group. The IR spectra of the compounds $4 \mathbf{a}-\mathbf{g}$ showed a broadband at $3437-3426 \mathrm{~cm}^{-1}$ due to $\mathrm{NH}$ vibrations. The IR spectra showed $\mathrm{C}=\mathrm{O}$ group of 1,2,4-triazolinone ring at $1715-1704 \mathrm{~cm}^{-1}$ and $\mathrm{C}=\mathrm{O}$ of acetyl group appeared at 1627 $1620 \mathrm{~cm}^{-1}$. The absence of the $\mathrm{C}=\mathrm{O}$ at $1609 \mathrm{~cm}^{-1}$ evidences the formation of the pyrazole ring. The $\mathrm{C}=\mathrm{N}$ group showed a band at $1594-1519 \mathrm{~cm}^{-1}$.

The $\mathrm{H}_{\mathrm{A}}$ and $\mathrm{H}_{\mathrm{B}}$ protons appeared as doublet due to geminal and vicinal coupling. These $\mathrm{H}_{\mathrm{A}}$ and $\mathrm{H}_{B}$ differ in coupling with the $\mathrm{Hx}$, and hence, they are also anisogamous. The $\mathrm{H}_{\mathrm{A}}$ proton appears as doublet of doublet in the range $\delta$ $3.109-3.31 \mathrm{ppm}$. The $\mathrm{H}_{\mathrm{B}}$ also appeared as doublet of doublet at $\delta 3.72-4.25 \mathrm{ppm}$. where $J_{\mathrm{BA}}$ is in the range $12.25-17.23 \mathrm{~Hz}$. The $H x$ always appeared as four-line spectrum in the range $\delta 3.72-$ $5.56 \mathrm{ppm}$. The ${ }^{1} \mathrm{H}$ NMR spectra of these compounds $2 \mathrm{a}-\mathrm{g}$ showed a singlet at $\delta 8.23-9.50 \mathrm{ppm}$. $\left(\mathrm{D}_{2} \mathrm{O}\right.$ exchangeable) for the $\mathrm{NH}_{2}$ protons. The singlets at $\delta 2.30-2.40 \mathrm{ppm}$. and 2.45$2.47 \mathrm{ppm}$. were observed for methyl protons of triazolinone $\left(\mathrm{C}_{5}-\mathrm{CH}_{3}\right)$ and that of acetyl group respectively. Another singlet was observed around $\delta 8.55-9.99 \mathrm{ppm}$. was due to the imine proton and the aromatic protons were resonated in the range $\delta 7.19-8.69 \mathrm{ppm}$. The ${ }^{1} \mathrm{H}$ NMR spectra of the compounds 3a-g showed a singlet for acetyl $\mathrm{CH}_{3}$ at $\delta 2.30-$ $2.37 \mathrm{ppm}$. and a singlet at $\delta 1.68-1.97 \mathrm{ppm}$. for the two $\mathrm{CH}_{3}$ groups of the 2,4-dione; the $\mathrm{C}_{5}-\mathrm{CH}_{3}$ appeared at $\delta 2.45-$ $2.49 \mathrm{ppm}$., and the imine $-\mathrm{CH}$ appeared at $\delta 8.15-9.99 \mathrm{ppm}$. The NH proton was observed at $\delta 5.53-5.57 \mathrm{ppm}$. $\left(\mathrm{D}_{2} \mathrm{O}\right.$ exchangeable). The ${ }^{1} \mathrm{H}$ NMR spectra of compounds $4 \mathbf{a}-\mathbf{g}$ showed a singlet for acetyl $\mathrm{CH}_{3}$ at $\delta 1.58-2.08 \mathrm{ppm}$. and the two $\mathrm{CH}_{3}$ protons of the pyrazole ring as two singlets at $\delta 2.29$ $2.35 \mathrm{ppm}$. and $\delta 2.36-2.47 \mathrm{ppm}$. The $\mathrm{C}_{5}-\mathrm{CH}_{3}$ also appeared at $\delta 2.45-2.52 \mathrm{ppm}$. as singlet. The compounds $2 \mathbf{e}, 3 \mathbf{e}$, and 4e showed a singlet for three protons of $\mathrm{C}_{5}-\mathrm{CH}_{3}$ in the range 2.29-2.37 ppm. The compounds $\mathbf{2 f}$, $3 \mathbf{f}$, and $\mathbf{4 f}$ showed a singlet for $-\mathrm{OH}$ at $5.15,5.60$, and $5.50 \mathrm{ppm}$., respectively. Also, singlets for $-\mathrm{OCH}_{3}$ at $\delta 3.72,3.75$, and $3.11 \mathrm{ppm}$. were observed in the compounds $\mathbf{2} \mathbf{g}, \mathbf{3} \mathbf{g}$, and $\mathbf{4} \mathbf{g}$.

\section{Biological Activity}

Further, in the present investigation, attention has also been diverted on structure activity relationship (SAR) by way of computational studies applying Osiris property explorer and analyzed for their drug score. The synthesized title compounds were also screened for antibacterial and antifungal activities and calculated the IC 50 values (graphs are provided in the Supplementary file) (See Supplementary Material available online at http://dx.doi.org/10.1155/2013/909706). 


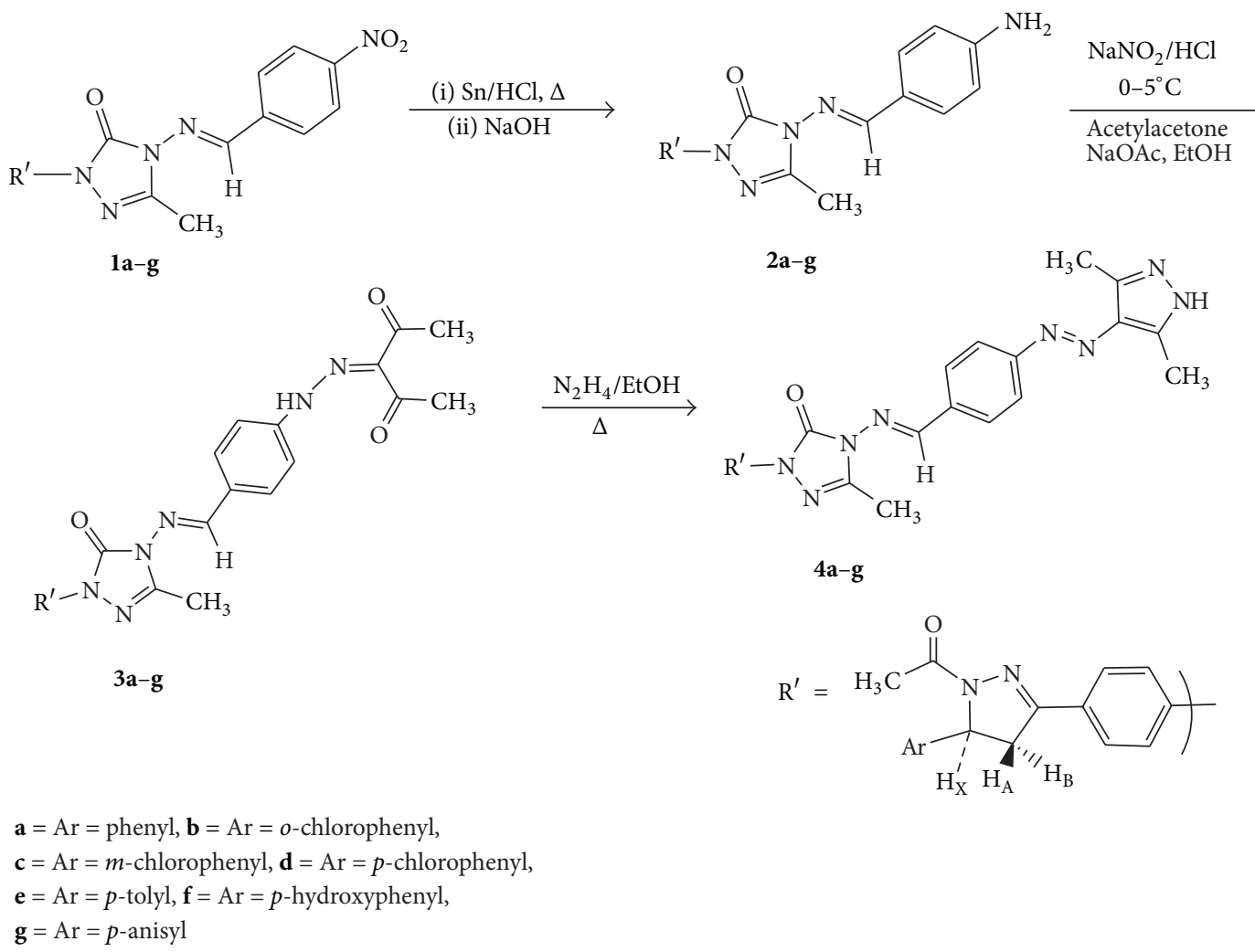

Figure 1

9.1. Molecular Osiris Property Explorer. It was possible to predict the biological activity of all the synthesized compounds in terms of their toxicity by employing toxicity risk assessment through Osiris property explorer which calculates on-the-fly various drug-relevant properties whenever a structure is valid. Prediction results are valued and color coded $[22,23]$. Properties with high risks of undesired effects like mutagenicity or a poor intestinal absorption are shown in red, whereas a green color indicates drug-conform behavior. In the latter study, all the compounds were evaluated for the presence of various toxicity parameters like mutagenicity, tumorigenicity, reproductive affective effects, and irritation. In the Osiris explorer tool, the drug score is calculated based on the combination of toxicity risks (mutagenicity, tumorigenicity, irritation, and reproduction), drug likeness, and some physicochemical parameters such as $c \log P, \log S$ (solubility), and molecular weight in one handy value than may be used to judge the compound's overall potential to qualify for a drug (based on the Lipinski rule of five). The title compounds do not violate the Lipinski rule and they fall well in the range. The target compounds showed moderate to good drug score $(0.12-0.36)$ that revealed their potential as safe lead compounds. The drug likeness value ranged from -3.14 to -0.44 , whereas the drug score ranged from 0.04 to 0.05 . The chloro substituent in the compounds $\mathbf{4 b}, \mathbf{4 c}$, and 4d was shifted to different positions (ortho, para, and meta) to study the change on the positional effect of substituent. Interestingly, these compounds showed almost the same drug score which indicates that there is no positional effect on these compounds. The compound $\mathbf{4 g}$ which has $p$-anisyl group showed less drug likeness and also the drug score was less. The compounds $\mathbf{4} \mathbf{e}$ and $\mathbf{4 f}$ which have electron donating groups show good drug score as depicted in Table 3. The compound $\mathbf{4} \mathbf{a}$ has also shown diversified effects based on drug likeness and drug score, but $c \log P$ values are well within the range as mentioned by the rule.

9.2. Antimicrobial Activity. MIC values for the in vitro antibacterial studies of the compounds $4 \mathbf{a}-\mathbf{g}$ and the standard are represented in Table 4 which fall at $09.00-21.00 \mathrm{mg} / \mathrm{mL}$ for antibacterial, and antifungal lies in the range 24.00$72.00 \mathrm{~g} / \mathrm{mL}$. The antibacterial activity of the compounds $\mathbf{4 a}$, $\mathbf{4 e}, \mathbf{4 f}$, and $\mathbf{4 g}$ against $S$. typhi and B. pyogenes showed excellent potencies compared to standard drugs gentamycin. The compounds $\mathbf{4 a}$ and $\mathbf{4 g}$ (phenyl, p-anisyl) have shown excellent potency against $S$. typhi. The compounds $\mathbf{4 a}$ and $\mathbf{4 f}$ (phenyl, p-hydroxy) have shown excellent potency against $B$. pyogenes. The compound $\mathbf{4 e}$ has shown good potency against both the bacterial strains tested. The antibacterial activity may be attributed towards the electron donating groups attached to the phenyl ring. The compounds $\mathbf{4 b}, \mathbf{4 c}$, and $\mathbf{4 d}$ have shown moderate potencies towards antibacterial activity. The compounds $\mathbf{4 b}, \mathbf{4 c}$, and $\mathbf{4 d}$ have good results towards antifungal activity. The compound $\mathbf{4 d}$ ( $p$-chloro) has shown excellent potency against both the fungal strains $A$. niger and C. albicans compared to standard drug amphotericin. The other two compounds $\mathbf{4 b}$ and $\mathbf{4 c}$ have shown good results against both strains tested. The antifungal activity may be due 


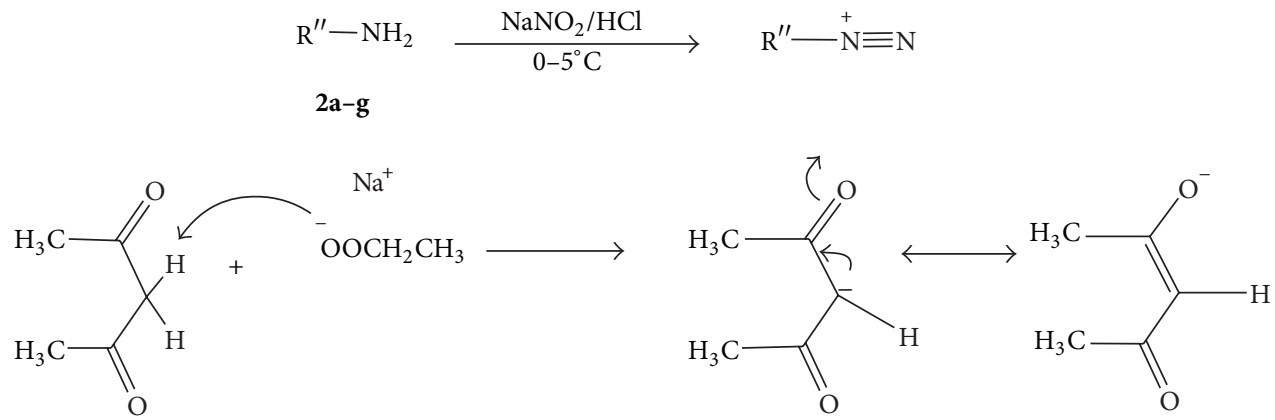

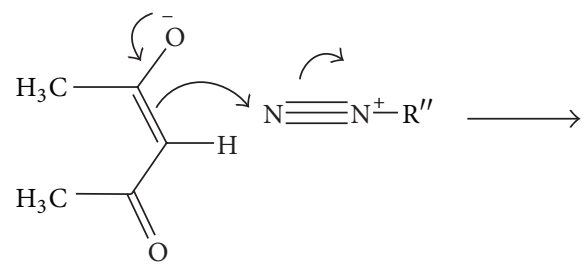<smiles>[R]N=NC(C(C)=O)C(C)=O</smiles>

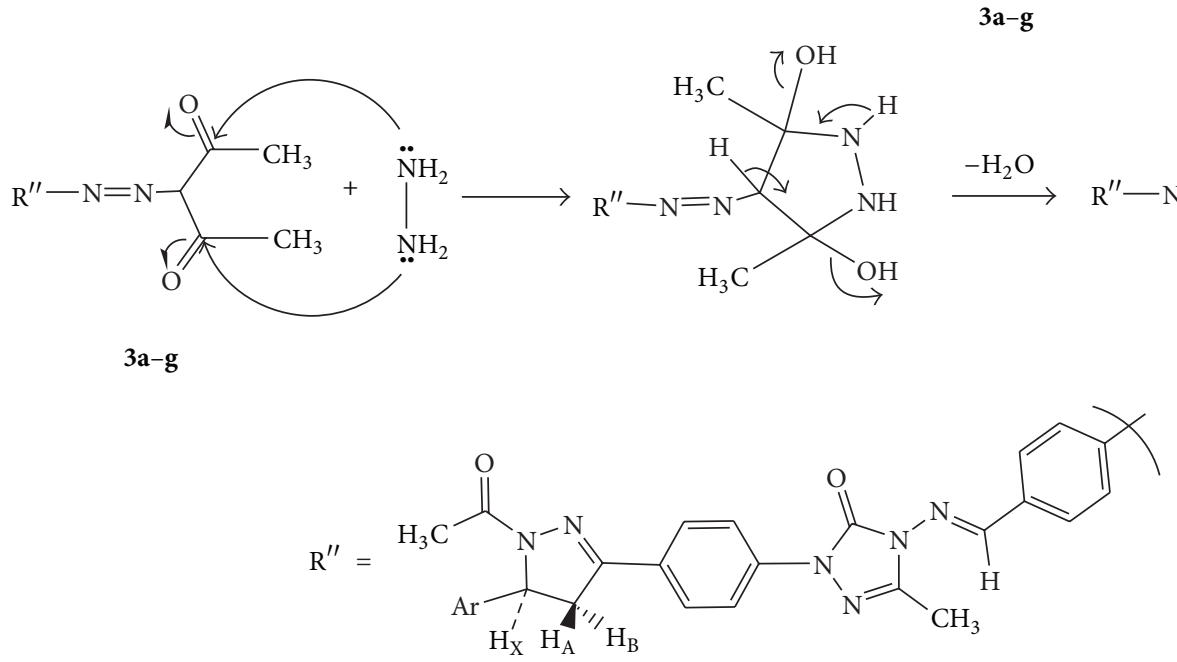

Figure 2

to the presence of halogen group on the phenyl ring. All other compounds have shown moderate activity against the fungal strains. From the results, it is apparent that among the title compounds, all of them, have shown excellent to moderate activity at $9.00-21.00 \mathrm{mg} / \mathrm{mL}$ and $24.00-72.00 \mathrm{mg} / \mathrm{mL}$ against all the screened bacteria and fungi. The results are in well agreement with the drug scores obtained from the Osiris property explorer. MIC values of all the triazole derivates $4 \mathbf{a}-$ g are excellent and promising because of the presence two pyrazole rings in a single moiety making them more potent towards the bacterial and fungal strains.

The IC 50 values of antimicrobial activity revealed that the compounds (4f and $\mathbf{4 g}$ ) and (4a and $\mathbf{4 b}$ ) have shown very good antifungal activity against $A$. niger and C. albicans, respectively, whereas the compounds ( $\mathbf{4 b}$ and $\mathbf{4 g}$ ) and $\mathbf{4 c}$ are potent against $S$. typhi and B. pyogenes, respectively.
TABLE 4: Antimicrobial activities of the compounds (MIC, $\mathrm{mg} / \mathrm{mL}$ ) $4 a-g$.

\begin{tabular}{lcccc}
\hline Entry no. & S. typhii & B. pyogenes & A. niger & C. albicans \\
\hline $\mathbf{4 a}$ & 18.0 & 21.0 & 40.0 & 24.0 \\
$\mathbf{4 b}$ & 12.0 & 10.0 & 65.0 & 42.0 \\
$\mathbf{4 c}$ & 09.00 & 13.0 & 60.0 & 40.0 \\
$\mathbf{4 d}$ & 14.0 & 09.00 & 72.0 & 43.0 \\
$\mathbf{4 e}$ & 15.0 & 18.0 & 44.0 & 27.0 \\
$\mathbf{4 f}$ & 16.0 & 22.0 & 38.0 & 25.0 \\
$\mathbf{4 g}$ & 21.0 & 19.0 & 43.0 & 33.0 \\
Gentamycin & 25 & 25 & - & - \\
Amphotericin & - & - & 100 & 50 \\
Control & DMSO & DMSO & DMSO & DMSO \\
\hline
\end{tabular}




\section{Conclusion}

In conclusion, we have developed a simple and efficient method for the synthesis of novel pyrazolyl triazole derivatives through reduction of nitro group and further reacting with acetyl acetone and hydrazine hydrate. We also believe that the procedural simplicity, the efficiency, and the easy accessibility of the reaction partners give access to an array of heterocyclic frameworks. The results of the antimicrobial activity (MIC and IC 50) revealed that all of the 7 compounds showed excellent to moderate inhibition against the bacteria and fungi screened.

\section{Conflict of Interests}

The authors confirm that this paper has no conflict of interests.

\section{Acknowledgments}

The authors are thankful to the USIC for spectral IR, ${ }^{1} \mathrm{H}$ NMR, MS, and CHN analyses. Tasneem Taj is thankful to the UGC, New Delhi, for the award of the RFSMS fellowship.

\section{References}

[1] S. G. Mallur and B. V. Badami, "Transformation of the sydnone ring into oxadiazolinones. A convenient one-pot synthesis of 3-aryl-5-methyl-1,3,4-oxadiazolin-2-ones from 3-arylsydnones and their antimicrobial activity," Farmaco, vol. 55, no. 1, pp. 6567, 2000.

[2] D. L. Browne and J. P. A. Harrity, "Recent developments in the chemistry of sydnones," Tetrahedron, vol. 66, no. 3, pp. 553-568, 2010.

[3] C. Wu, Y. Fang, R. C. Larock, and F. Shi, "Synthesis of $2 H-$ indazoles by the $[3+2]$ cycloaddition of arynes and sydnones," Organic Letters, vol. 12, no. 10, pp. 2234-2237, 2010.

[4] Tasneem Taj, R. R. Kamble, P. P. Kattimani, and B. V. Badami, "Synthetic utility of sydnones: synthesis of pyrazolines derivatized with 1, 2, 4-triazoles as anti-hyperglycemic, antioxidant agents and their DNA cleavage study," Medicinal Chemistry Research, vol. 21, pp. 3709-3719, 2011.

[5] R. Shapiro, R. DiCosimo, S. M. Hennessey, B. Stieglitz, O. Campopiano, and G. C. Chiang, "Discovery and development of a commercial synthesis of azafenidin," Organic Process Research and Development, vol. 5, no. 6, pp. 593-598, 2001.

[6] D. J. Dumas, “Process for the preparation of sulfentrazone," US Patent 5990315, 1999.

[7] J. Q. Weng, L. Wang, and X. H. Liu, "Synthesis, crystal structure and herbicidal activity of a 1, 2, 4-triazol-5(4H)-one derivative," Journal of Chemical Society of Pakistan, vol. 34, pp. 1248-1252, 2012.

[8] L. Wang, Y. Ma, X. Liu, Y. Li, H. Song, and Z. Li, "Synthesis, herbicidal activities and comparative molecular field analysis study of some novel triazolinone derivatives," Chemical Biology and Drug Design, vol. 73, no. 6, pp. 674-681, 2009.

[9] D. J. Ye, X. L. Feng, and Z. H. Zhang, "Synthesis and crystal structure of 1,2,4-Triazol-5(4H)-one derivative," Asian Journal of Chemistry, vol. 24, pp. 5286-5288, 2012.
[10] K. T. Potts, “The chemistry of 1,2,4-triazoles," Chemical Reviews, vol. 61, no. 2, pp. 87-127, 1961.

[11] H. G. Garg and C. Prakash, "Nitroazoles: synthesis, structure and applications," Journal of Medicinal Chemistry, vol. 14, pp. 649-651, 1961.

[12] D. M. Bailey, P. E. Hansen, A. G. Hlavac et al., "3,4-Diphenyl$1 \mathrm{H}$-pyrazole-1-propanamine antidepressants," Journal of Medicinal Chemistry, vol. 28, no. 2, pp. 256-260, 1985.

[13] P. G. Baraldi, M. G. Pavani, M. D. C. Nuez et al., "Antimicrobial and antitumor activity of $\mathrm{N}$-heteroimmine-1,2,3-dithiazoles and their transformation in triazolo-, imidazo-, and pyrazolopirimidines," Bioorganic and Medicinal Chemistry, vol. 10, no. 2, pp. 449-456, 2002.

[14] M. Z. Wisniewski, W. J. Surga, and E. M. Opozda, "Novel $\mathrm{Ru}$ (III), $\mathrm{Rh}(\mathrm{III}), \mathrm{Pd}(\mathrm{II})$ and $\mathrm{Pt}(\mathrm{II})$ complexes with ligands incorporating azole and pyrimidine rings," Transition Metal Chemistry, vol. 19, 1994.

[15] T. A. K. Al-Allaf and L. J. Rashan, "Cis- and trans- platinum and palladium complexes: a comparative study review as antitumour agents," Bollettino Chimico Farmaceutico, vol. 140, no. 3, pp. 205-210, 2001.

[16] J. Elguero, A. R. Katritzky, C. W. Pees, and E. F. Scriven, Comprehensive Heterocyclic Chemistry II, vol. 3, Pergamon Press, Oxford, UK, 1875.

[17] C. J. Holmes, R. K. Ausman, C. W. Walter, and R. B. Kundsin, "Activity of antibiotic admixtures subjected to different freezethaw treatments," Drug Intelligence and Clinical Pharmacy, vol. 14, no. 5, pp. 353-357, 1980.

[18] C. A. Lipinski, "Lead- and drug-like compounds: the rule-offive revolution," Drug Discovery Today, vol. 1, no. 4, pp. 337-341, 2004.

[19] http://www.organic-chemistry.org/prog/peo/.

[20] E. J. Threfall, I. S. T. Fisher, L. Ward, H. Tschape, and S. Gerner, "OIE international standards on antimicrobial resistance," Microbial Drug Resistance, vol. 5, pp. 195-198, 2003.

[21] R. D. Walker, J. F. Prescot, J. D. Baggot, R. D. Walker, and I. A. Ames, "Antimicrobial susceptibility testing and interpretation of results," in Antimicrobial Therapy in Veterinary Medicine, vol. 12, Iowa State University Press, 2000.

[22] P. P. Kattimani, S. V. Raikar, R. R. Kamble, M. Y. Kariduraganavar, and R. K. Hunnur, "An expeditious synthesis of 1,2,4triazolinones appended to 1,3-thiazoles using zinc triflate as catalyst," Main Group Chemistry, vol. 10, no. 2, pp. 165-175, 2011.

[23] T. Taj, R. R. Kamble, T. M. Gireesh, R. K. Hunnur, and S. B. Margankop, "One-pot synthesis of pyrazoline derivatised carbazoles as antitubercular, anticancer agents, their DNA cleavage and antioxidant activities," European Journal of Medicinal Chemistry, vol. 46, no. 9, pp. 4366-4373, 2011. 

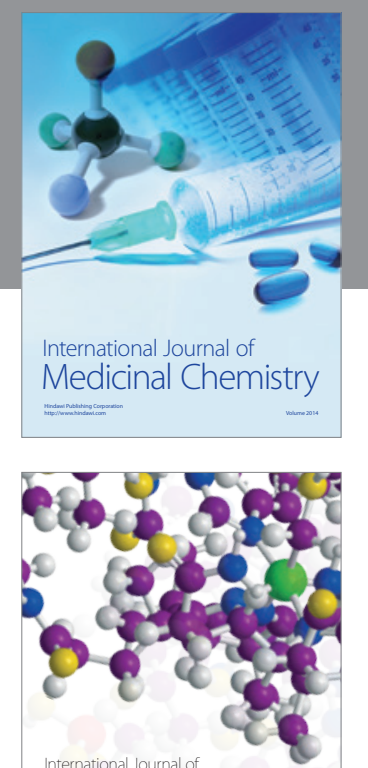

\section{Carbohydrate} Chemistry

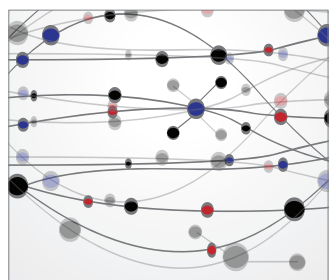

The Scientific World Journal
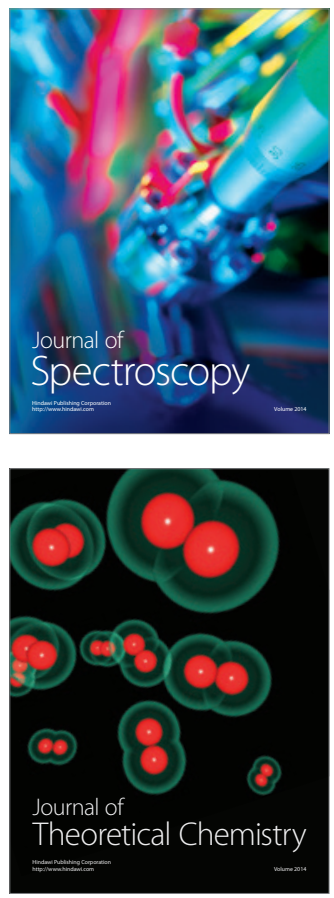
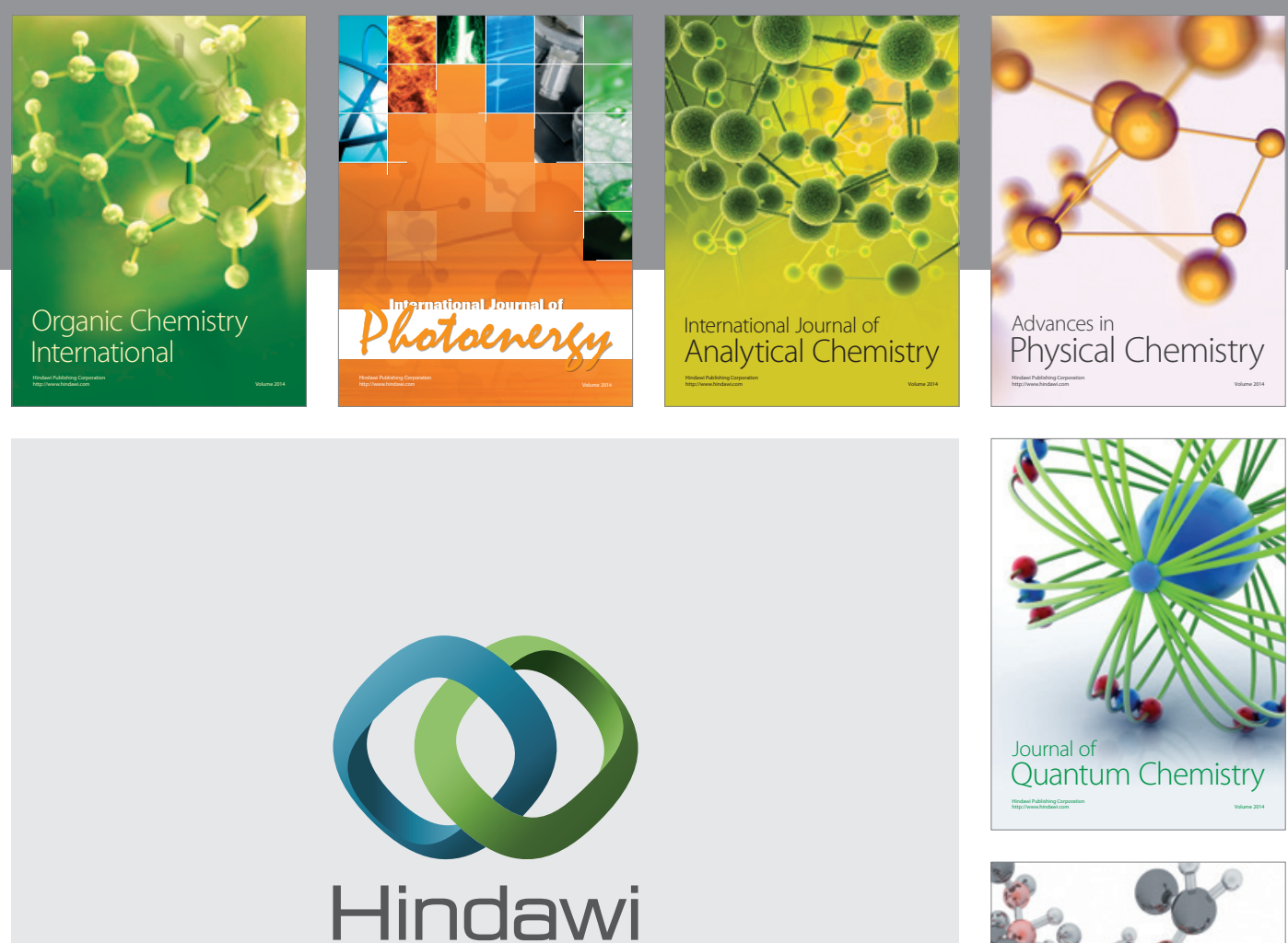

Submit your manuscripts at

http://www.hindawi.com

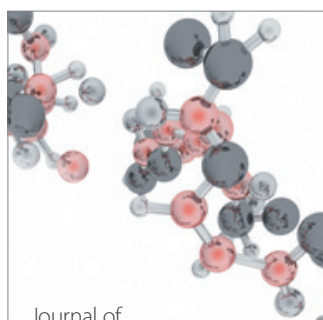

Analytical Methods

in Chemistry

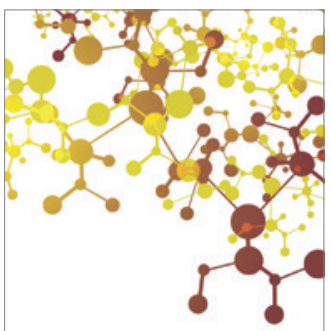

Journal of

Applied Chemistry

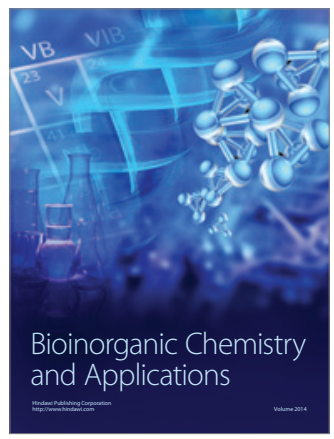

Inorganic Chemistry
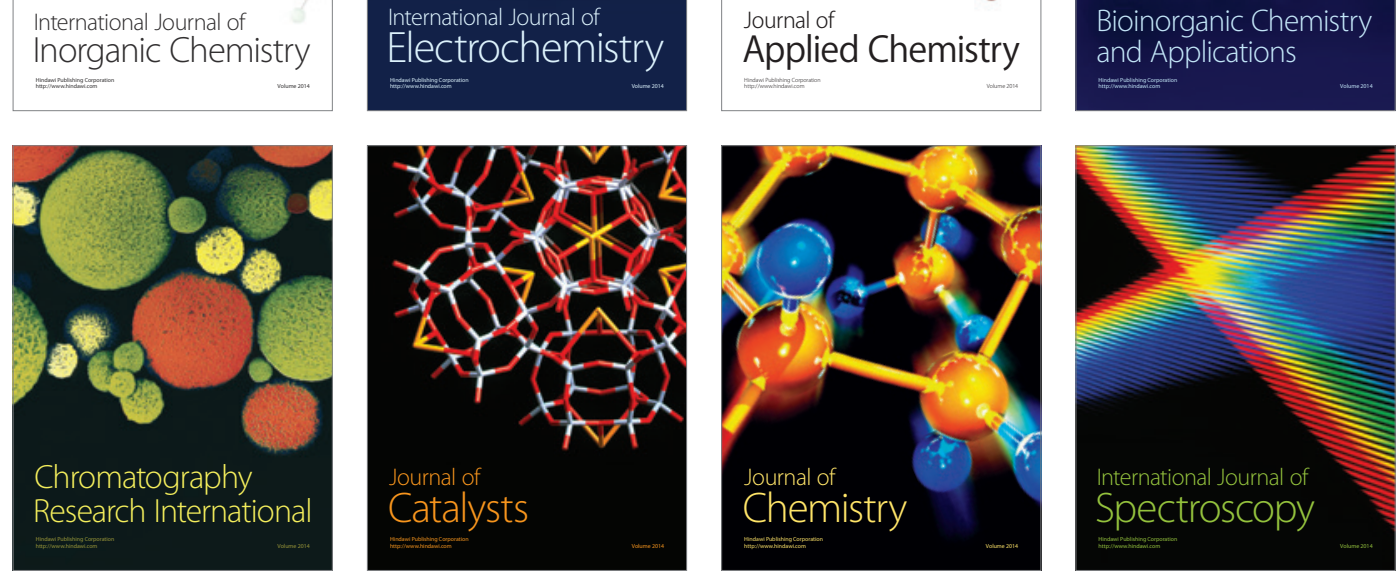